\title{
Orbito-Ethmoidal Rhabdomyosarcoma in an Adult Patient: A Case Report and Review of the Literature
}

\author{
Ilson Sepúlveda ${ }^{a, f} \quad$ M. Loreto Spencer ${ }^{b}$ Claudia Cabezas $^{b, d}$ \\ Maria Olga Platino ${ }^{g}$ Max Schorwer ${ }^{c}$ Pablo Ortega ${ }^{a}$ David Ulloa $^{e}$ \\ ${ }^{a}$ Otolaryngology - Head and Neck Surgery Service, ${ }^{b}$ Pathology Department, and \\ 'Oncology Service, General Hospital of Concepción, ${ }^{d}$ Católica de la Santísima Concepción \\ University, and ${ }^{\mathrm{e}}$ School of Medicine, San Sebastián University, Concepción, and ${ }^{\mathrm{f}}$ Faculty of \\ Dentistry, Finis Terrae University, Santiago, Chile; ${ }^{9}$ Health Science Center at Houston, \\ University of Texas, Houston, Tex., USA
}

\section{Key Words}

Computed tomography · Magnetic resonance imaging · Ethmoidal region ·

Rhabdomyosarcoma $\cdot$ Radiochemotherapy

\begin{abstract}
We report a patient who presented to the ENT service complaining of nasal obstruction, exophthalmos, edema and ipsilateral facial congestion. Imaging studies revealed an aggressive noncalcified solid mass centered in the left nasoethmoidal region and heterogeneous avid enhancement following contrast media injection. Subsequently, a biopsy confirmed the presence of solid alveolar rhabdomyosarcoma. The patient was treated with chemoradiation therapy for 7 weeks. Due to the advanced stage of the disease, the patient was enrolled in a palliative care and pain control program.

(c) 2014 S. Karger AG, Basel
\end{abstract}

\section{Introduction}

Rhabdomyosarcoma (RMS) is a malignant tumor of striated muscle origin and derives from primitive mesenchyme that retains its capacity for skeletal muscle differentiation. It is one of the most common sarcomas in newborns and children. Approximately $35 \%$ of all RMS occur in the head and neck. The combined use of chemoradiotherapy and surgery improves the survival rate significantly, namely up to 5 years. 
Sepúlveda et al.: Orbito-Ethmoidal Rhabdomyosarcoma in an Adult Patient: A Case Report and Review of the Literature

\section{Case Presentation}

We report on a 42-year-old male patient who, without a significant clinical history, presented to the ENT service complaining of nasal obstruction, exophthalmos, edema and ipsilateral facial congestion. CT and MRI were performed. CT showed an aggressive, noncalcified, solid mass centered in the left nasoethmoidal region invading the left side of the frontal sinus, left maxillary sinus and the left orbit. There was no evidence of intracranial invasion (fig. 1, fig. 2). T2-weighted MRI showed a mildly hypointense, solid mass centered in the left nasoethmoidal region invading the left side of the frontal sinus. The mass was abutting the left. The tumor was also invading the left orbit with lateral displacement of the medial rectus muscle and globe (fig. 3). Intracranial invasion and heterogeneous avid enhancement of the mass was seen in the postcontrast fat-saturated images (fig. 4, fig. 5).

A biopsy was performed under local anesthetic. Immunohistochemistry tests were positive for desmin (fig. 6), myogenin (fig. 7), vimentin (fig. 8), actin (fig. 9), S-100, chromogenin and synaptophysin and negative for NSE (neuron-specific enolase). Final pathology reported a solid, alveolar RMS. The case was presented and discussed at the Head and Neck Tumor Board and a decision was made to initiate chemoradiation therapy consisting of 4 cycles of ifosfamide, doxoruvicine, vincristin and mesna. Follow-up imaging of the patient demonstrated disease progression with intracranial invasion. Conventional radiotherapy treatment was started with a total dose of $63 \mathrm{~Gy}$, administered in 1.8-Gy doses during 7 weeks (fig. 10). Disease progression was seen in spite of chemoradiotherapy. The patient was referred to the pain control and palliative care program.

\section{Discussion}

RMS is a malignant tumor with striated muscle differentiation deriving from primitive mesenchyme [1] that retains its capacity for skeletal muscle differentiation [2]. RMS was first described in the English literature in 1937 and in 1992 in children as a tumor mainly composed of bundles of cells with myogenic differentiation by immunohistochemical and ultrastructural analysis. Rubin et al. [3] described the first two examples of RMS with spindle cells in adults. Since then and until 2007, 21 cases have been described in the English literature [4].

This sarcoma is one of the most common soft tissue sarcomas in newborns, children, and young adults [5]. 20-25\% of the cardiac neoplasms in adults are sarcomas [6]. The annual incidence of RMS in the USA is 4.6 per million in subjects under 20 years of age. RMS may occur in all age groups but is more prevalent in the first and second decades of life, with a peak between 2 and 6 years of age [7], representing approximately $4-8 \%$ of all pediatric cancers [8]. Although head and neck tumors are rare in children [9], approximately $60 \%$ of all pediatric RMS cases occur in the head and neck [9-11].

RMS has different grades of striated muscle cell differentiation and it may occur in any part of the body [10]. Four different histopathological types have been described: embryonal, alveolar, pleomorphic and undifferentiated [7], with embryonal and alveolar being the two most common histopathological types described in childhood [12]. The embryonal type represents $70 \%$ of all cases, is mainly seen in children under the age of 12 and carries the best prognosis. The alveolar type is more frequent in the extremities, affecting an older age group. It generally shows the chromosomal translocation t2:13; p35-14, carrying a more ominous prognosis than the other types of RMS [13]. The pleomorphic variety is less frequent and occurs more often in an older population [7]. 
Anatomically, RMS are classified as parameningeal, orbital, nonparameningeal and nonorbital. Approximately $40 \%$ of all newly diagnosed RMS arise in head and neck structures including parameningeal sites $(16 \%$ of all cases, and almost half of all head and neck cases), the orbit or eyelid (10\% of all cases), and other nonorbit, nonparameningeal sites $(10 \%$ of all cases). The parameningeal tumors carry the worst prognosis $[7,14]$.

The parameningeal sites include the nose, nasopharynx, paranasal sinuses, middle ear, mastoid, infratemporal fossa and pterygopalatine fossa. Soderberg described the first case of an aggressive RMS in the middle ear [15]. RMS of the temporal bone carries a poor prognosis due to its proximity to the brain and vital structures. Jaffe et al. found a 2-year survival rate of $0 \%$ in a review of 20 cases from the literature [16].

The nonorbital and nonparameningeal forms include the scalp, parotid gland, oropharynx, larynx and oral cavity. The tongue, palate and cheeks are the most common oral sites [7]. Of the $35 \%$ of all RMS that occur in the head and neck, $10-12 \%$ present in the oral cavity. RMS rarely occur in the salivary glands [17].

RMS can have a syndromic presentation such as their association with BeckwithWiedemann syndrome (10\% of all cases) [18]. Metastasis occurs by hematogenous or lymphatic spread, most commonly to the lungs, bones and brain [7]. The prognosis is influenced by the anatomic location at the time of presentation, patient's age, completeness of resection, extent of metastasic disease and tumor histology [19].

A multidisciplinary treatment approach is most effective. The combined use of chemoradiotherapy and surgery has significantly improved the survival rate of head and neck RMS to 5 years in the last 30 years [7]. A study indicates that approximately $65 \%$ of the children diagnosed with RMS survive with combined therapy [9]. In the pediatric parameningeal RMS cases, the treatment of choice is chemoradiotherapy, with surgery having a limited role due to the relative inaccessibility of the lesions and associated surgical morbidity [20]. Improved and innovative operative techniques of craniofacial surgical reconstruction have resulted in satisfactory functional and cosmetic results [9].

In conclusion, RMS is a rare head and neck tumor that occurs in the adult population and has a poor prognosis despite aggressive therapy.

\section{Disclosure Statement}

The authors have no conflicts of interest to declare.

\section{References}

1 Miranda C, Caran E, Alves M, Barreto A, Lopez I: Rhabdomyosarcoma of the oral tissues - two new cases and literature review. Med Oral Patol Oral Cir Bucal 2006;11:136-140.

-2 Yasuda T, Perry K, Nelson M, Bui M, Nasir A, Goldschmidt R, Gnepp D, Bridge J: Alveolar rhabdomyosarcoma of the head and neck region in older adults: genetic characterization and a review of the literature. Hum Pathol 2009;40:341-348.

-3 Rubin BP, Hasserjian RP, Singer S, Janecka I, Fletcher JA, Fletcher CD: Spindle cell rhabdomyosarcoma (socalled) in adults: report of two cases with emphasis on differential diagnosis. Am J Surg Pathol 1998;22:459-464.

4 Goosens V, Van den Berghe I, De Clercq C, Casselman J: Radiation-induced mandibular adult spindle cell rhabdomyosarcoma. Int J Oral Maxillofac Surg 2008;37:395-397.

-5 Kariya S, Schachern P, Cureoglu S, Paparella M, Nishizaki K: Histopathological temporal bone study of the metastatic rhabdomyosarcoma. Auris Nasus Larynx 2009;36:221-223.

-6 Scott R, Jagirdar J: Right atrial botryoid rhabdomyosarcoma in an adult patient with recurrent pleomorphic rhabdomyosarcomas following doxorubicin therapy. Ann Diagn Pathol 2007;11:274-276. 
Sepúlveda et al:: Orbito-Ethmoidal Rhabdomyosarcoma in an Adult Patient: A Case Report and Review of the Literature

7 Fatusi O, Ajike S, Olateju S, Adebayo A, Gbolahan 0, Ogunmuyiwa S: Clinico-epidemiological analysis of orofacial rhabdomyosarcoma in a Nigerian population. Int J Oral Maxillofac Surg 2009;38:256-260.

8 Tan G, Shiran M, Hayati A, Sharifah N, Rohaizak M, Nurul AS: Alveolar rhabdomyosarcoma of the left hand with bilateral breast metastases in an adolescent female. J Chin Med Assoc 2008;71:639-642.

$>9$ Smith IM, Anderson PJ, Yuen T, Tan E, David DJ: Rhabdomyosarcoma of the mandible - long term management from childhood to adulthood. J Plast Reconstr Aesthet Surg. 2008;61:582-585.

10 Neves BMJ, Pontes PAL, Caran EM, Figueiredo C, Weckx LLM, Fujita RR: Head and neck rhabdomyosarcoma in childhood. Braz J Otorhinolaryngol 2003;69:24-27.

11 Dalfior D, Eccher A, Gobbo S, Brunelli M, Martignoni G, Menestrina F, Dalla P, Dvornik G: Primary pleomorphic rhabdomyosarcoma of the kidney in an adult. Ann Diagn Pathol 2008;12:301-303.

12 Duval M, Faingold R, Carret A, Daniel S: Nasal ala rhabdomyosarcoma misdiagnosed as a facial infection. Int J Pediatr Otorhinolaryngol Extra 2008;3:44-47.

13 Sbeity S, Abella A, Arcand P, Quintal M, Saliba I: Temporal bone rhabdomyosarcoma in children. Int J Pediatr Otorhinolaryngol 2007;71: 807-881.

14 Charytonowicz E, Cordon-Cardo C, Matushansky I, Ziman M: Alveolar rhabdomyosarcoma: is the cell of origin a mesenchymal stem cell? Cancer Lett 2009;279:126-136.

15 Soderberg F: Rhabdomyome epipharynge ayant envahi l'oreille et les meninges. Acta Otolaryngol 1933;18:453-459.

16 Jaffe B, Fox J, Batsakis J: Rhabdomyosarcoma of the middle ear and mastoid. Cancer 1971;27:29-37.

17 Lamovec J, Volavšek M: Sclerosing rhabdomyosarcoma of the parotid gland in an adult: case report and review of the literature. Ann Diagn Pathol 2009;13:334-338.

18 Kuroiwa M, Sakamoto J, Shimada A, Suzuki N, Hirato J, Park M, Sotomatsu M, Hayashi Y: Manifestation of alveolar rhabdomyosarcoma as primary cutaneous lesions in a neonate with Beckwith-Wiedemann syndrome. J Pediatr Surg 2009;44:31-35.

19 Leaphart C, Rodeberg D: Pediatric surgical oncology: management of rhabdomyosarcoma. Surg Oncol 2007;16:173-185.

20 Chawla S, Tapp H, Schembri M: Para-meningeal rhabdomyosarcoma with critical airway compromise: role of endoscopic debulking surgery. Int J Pediatr Otorhinolaryngol Extra 2007;2:243-249.

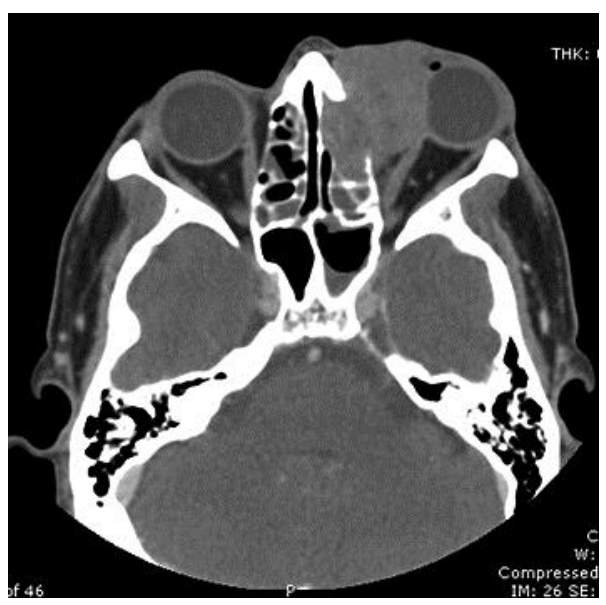

Fig. 1. Expansive process in the ethmoidal and orbital region. 


\section{Case Reports in Oncology}

Case Rep Oncol 2014;7:513-521

DOI: $10.1159 / 000365547$

Sepúlveda et al.: Orbito-Ethmoidal Rhabdomyosarcoma in an Adult Patient: A Case Report and Review of the Literature

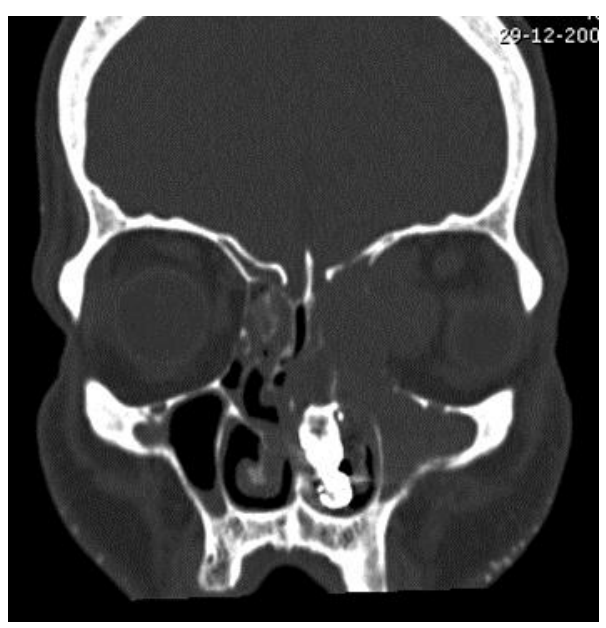

Fig. 2. Invasion of the left frontal and maxillary sinuses.

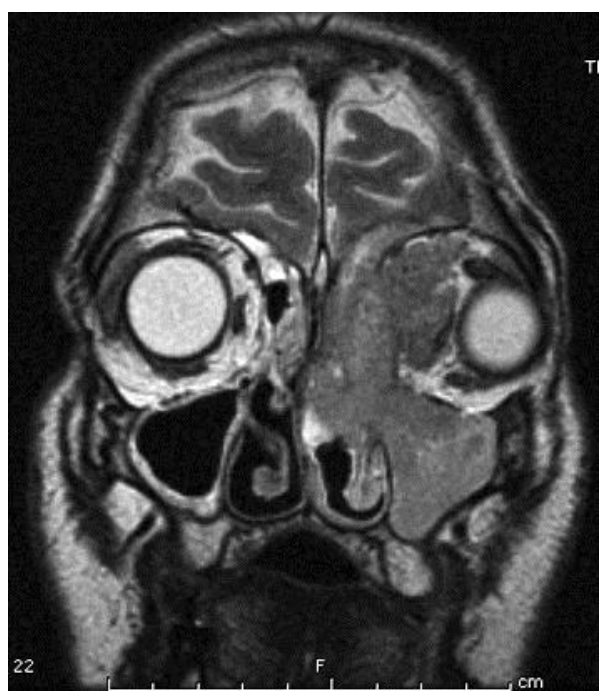

Fig. 3. MRI, T2 sequence. Mildly hypointense mass without intracranial invasion. 


\section{Case Reports in Oncology}

Case Rep Oncol 2014;7:513-521

DOI: $10.1159 / 000365547$

Sepúlveda et al:: Orbito-Ethmoidal Rhabdomyosarcoma in an Adult Patient: A Case

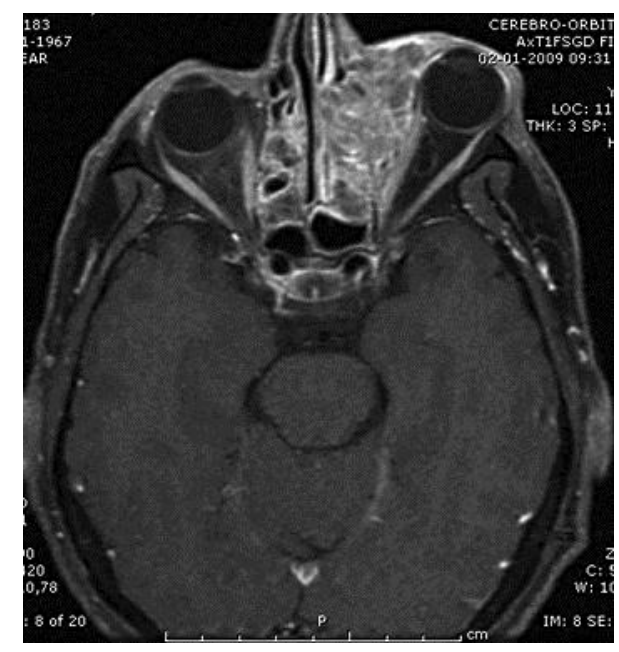

Fig. 4. T1-weighted MRI FSGD (fat sat and gadolinium). Heterogenous avid enhancement.

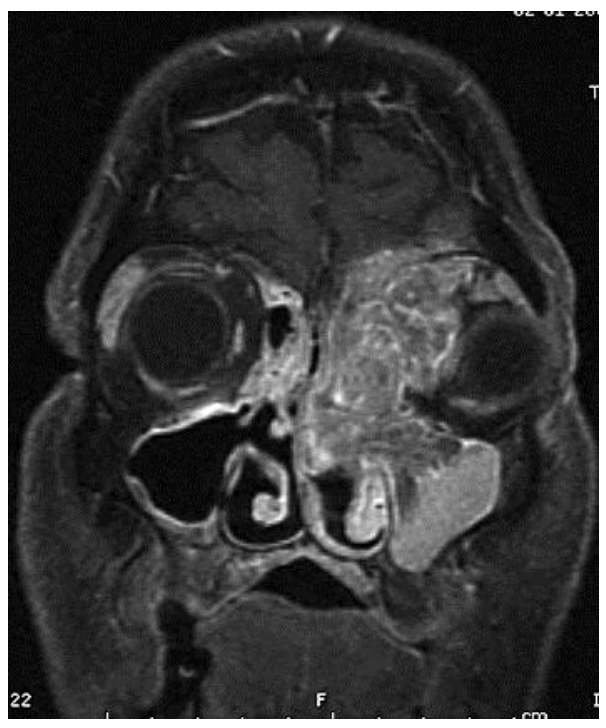

Fig. 5. T1-weighted MRI FSGD (fat sat and gadolinium). Lateral displacement of the globe. Mucous retention in the left maxillary sinus. 


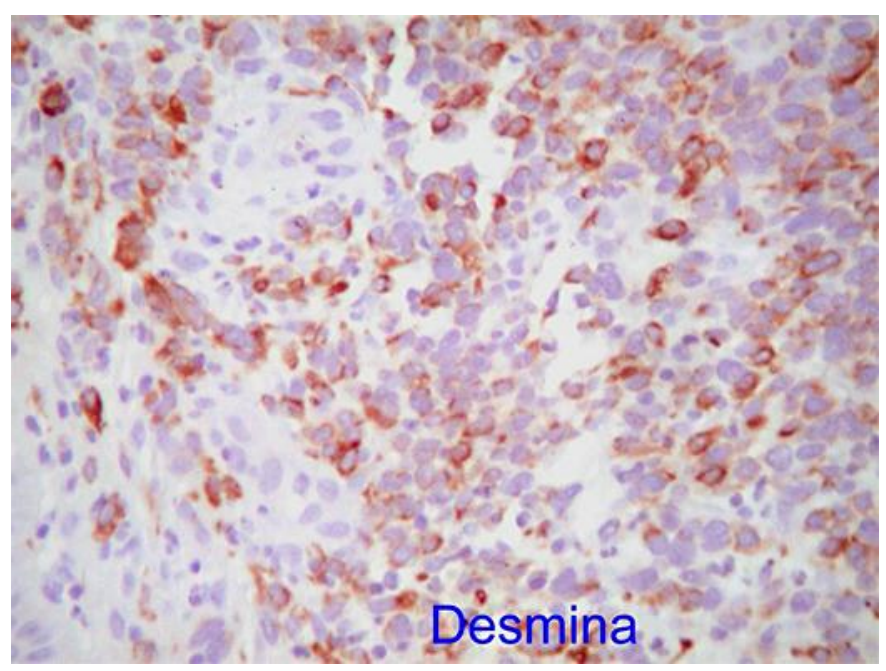

Fig. 6. Desmin-positive staining.

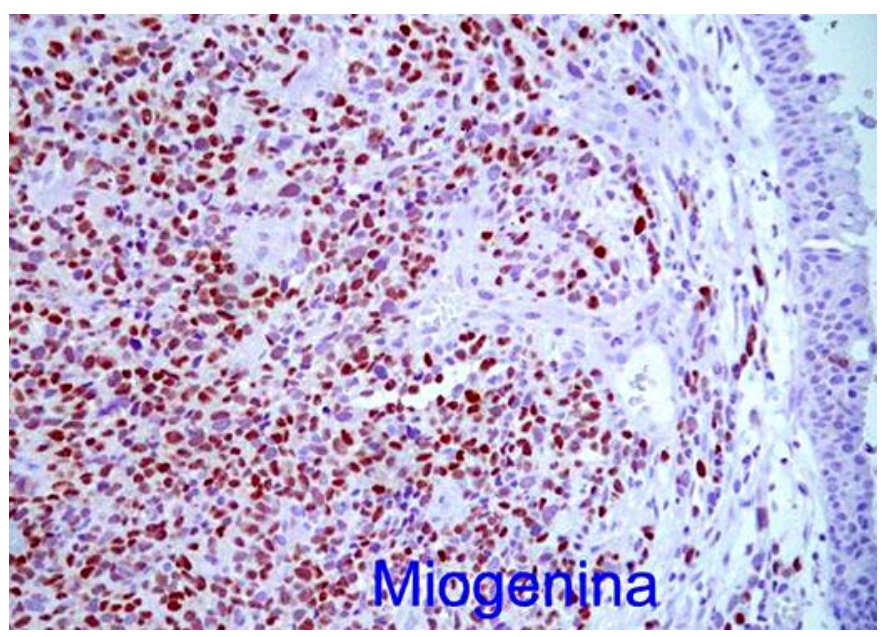

Fig. 7. Myogenin-positive staining. 


\section{Case Reports in Oncology}

\begin{tabular}{l|l}
\hline Case Rep Oncol 2014;7:513-521 \\
\hline DOI: 10.1159/000365547 & $\begin{array}{l}\text { @ 2014 S. Karger AG, Basel } \\
\text { www.karger.com/cro }\end{array}$ \\
\hline
\end{tabular}

Sepúlveda et al.: Orbito-Ethmoidal Rhabdomyosarcoma in an Adult Patient: A Case Report and Review of the Literature

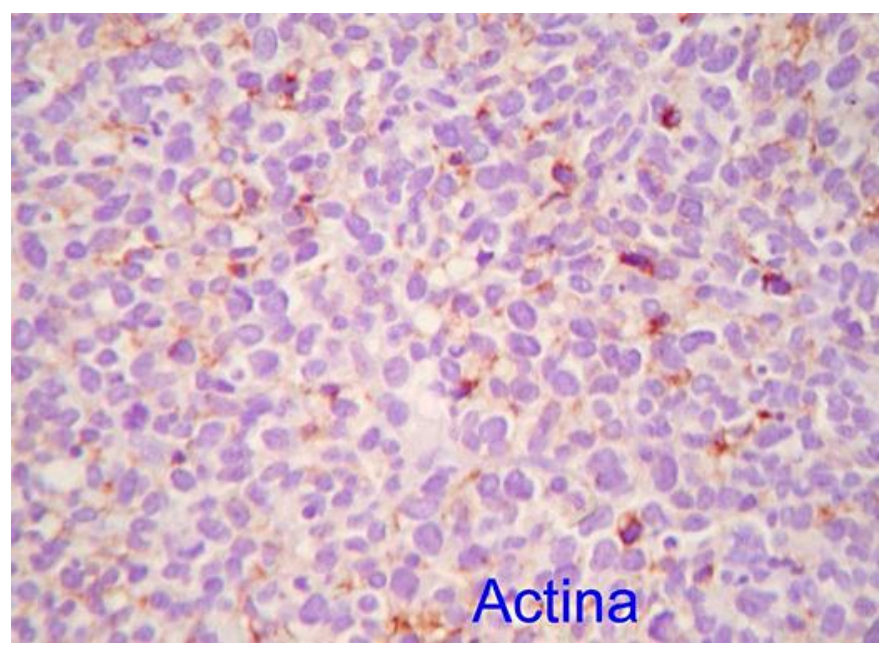

Fig. 8. Actin-positive staining.

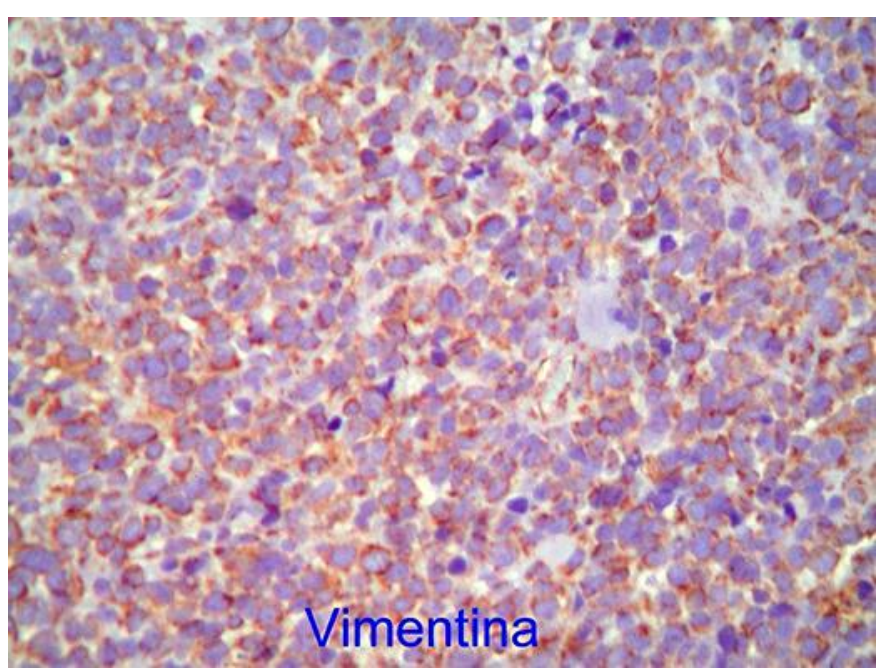

Fig. 9. Vimentin-positive staining. 
Case Rep Oncol 2014;7:513-521

DOI: $10.1159 / 000365547$

Sepúlveda et al.: Orbito-Ethmoidal Rhabdomyosarcoma in an Adult Patient: A Case Report and Review of the Literature

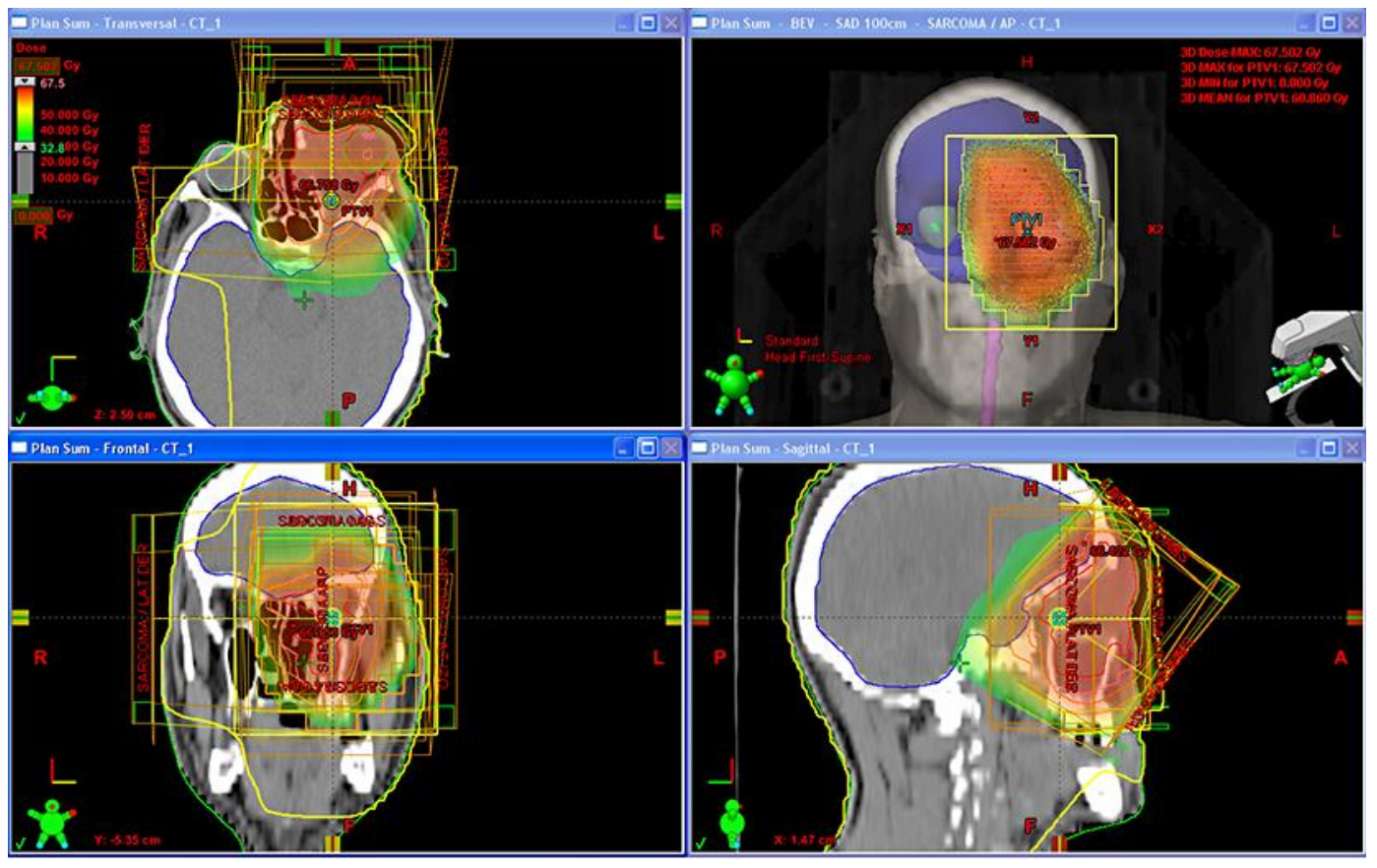

Fig. 10. Tridimensional conformal radiation plan. 